\title{
SNAP Declines Continue in 2016, but Not for Rural Places
}

\author{
Jessica A. Carson
}

$\mathrm{I}$ n 2016, 12.4 percent of households reported Supplemental Nutrition Assistance Program (SNAP, or food stamps) receipt, down 0.4 percentage point from 2015. Similar declines in suburbs and cities drove the national decrease, but the 14.8 percent of rural households receiving SNAP did not significantly change between 2015 and 2016. Median income in rural SNAP households, at $\$ 17,884$, was lower than in cities $(\$ 19,873)$ and suburbs $(\$ 24,583)$. Overall, SNAP receipt remains higher than before the Great Recession, though rates are slowly declining (see Figure 1). The share of SNAP households containing at least one worker increased between 2015 and 2016 (to 79.1 percent) as working families continue to struggle to make ends meet.

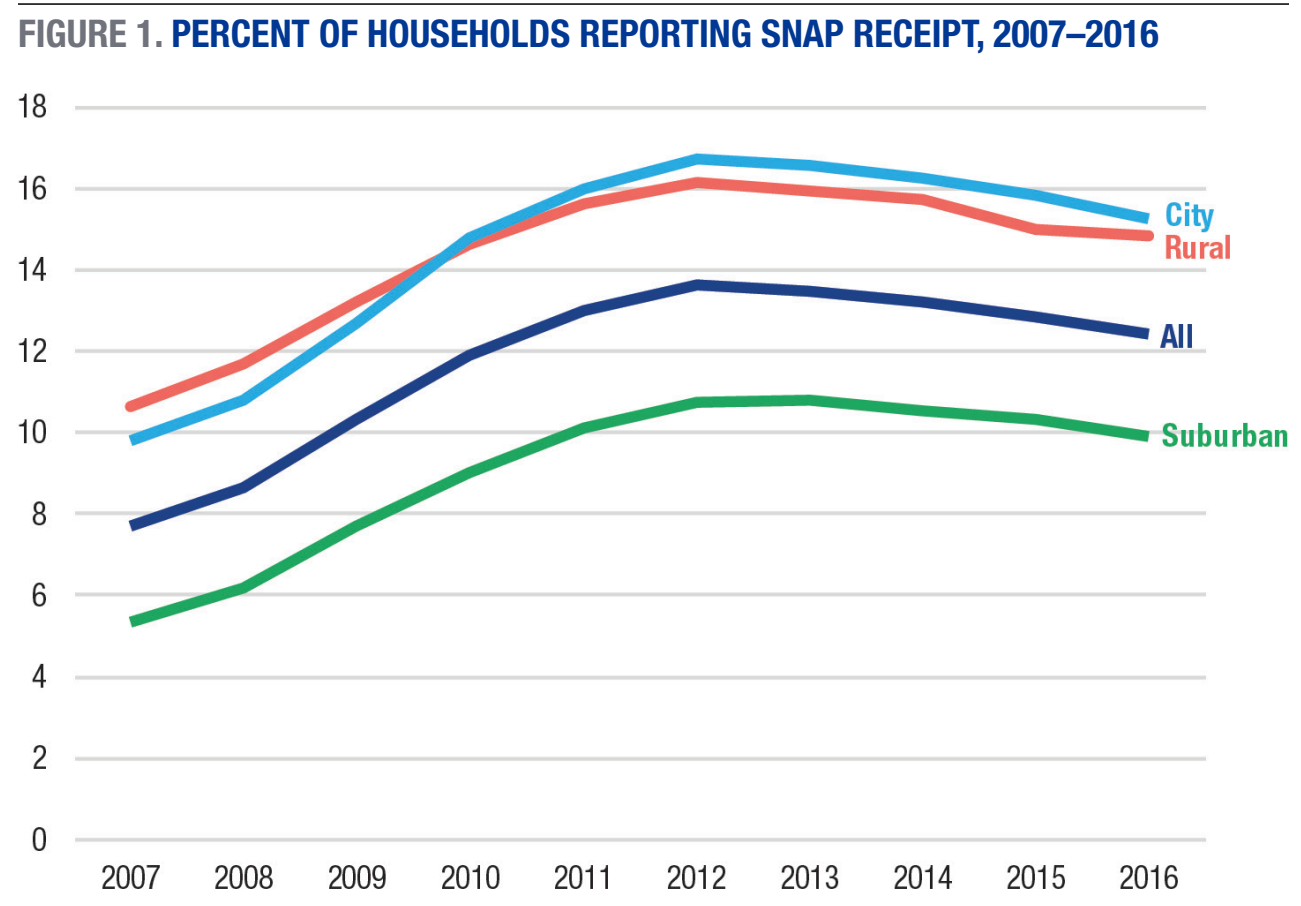

See related publications at carsey.unh.edu

- Rates of SNAP Receipt Stabilize or Drop in All Regions for First Time Since Great Recession (July 2015)

- SNAP Use Increased Slightly in 2012: In Struggling Economy, Both Traditional and New Populations Rely on SNAP to Avoid Hunger (November 2013)

This analysis was funded by the Annie E. Casey Foundation and the Wellspring Philanthropic Fund.

Source: American Community Survey, 1-year estimates, 2007-2016 